\title{
The task-based fMRI study on neural activity of internet gaming addiction among Malaysian adolescents: A stroop color task
}

\author{
${ }^{1}$ Nur Munirah Abdull Nasser, ${ }^{1}$ Mazlyfarina Mohamad, ${ }^{2}$ Lai Fong Chan, ${ }^{3}$ Subapriya \\ Suppiah, ${ }^{1}$ Ahmad Nazlim Yusoff, ${ }^{4}$ Aini Ismafairus Abd Hamid, ${ }^{2}$ Wan Salwina Wan \\ Ismail, ${ }^{5} \mathrm{Su}$ Tein $\mathrm{Sim}$ \\ ${ }^{1}$ Centre for Diagnostic, Therapeutic and Investigative Studies, Faculty of Health Sciences, Universiti \\ Kebangsaan Malaysia, Kuala Lumpur; ${ }^{2}$ Department of Psychiatry, Faculty of Medicine, Universiti \\ Kebangsaan Malaysia, Kuala Lumpur; ${ }^{3}$ Department of Radiology, Faculty of Medicine and Health \\ Sciences, Universiti Putra Malaysia. Serdang, Selangor; ${ }^{4}$ Department of Neurosciences, School of \\ Medical Sciences, Universiti Sains Malaysia, Kubang Kerian, Kelantan; ${ }^{5}$ ALH Specialist Clinic, \\ Petaling Jaya, Selangor, Malaysia.
}

\begin{abstract}
Background: Gaming can be very entertaining and through it, gamers are able to develop skills. However, it also may result in one's getting too obsessed with video games regardless of any circumstances. Unnoticed, it may develop an Internet gaming disorder (IGD). This study aimed to investigate the neural activation involved in cognitive flexibility using fMRI that being triggered by the Stroop color task among Malaysian youngsters and its correlation with designated psychological disorders. Methods: A total of 37 participants $(\mathrm{IGD}=19$, Control $=18)$ were recruited to partake in this study. The division of participants according to the cut-off point of IAT and IGDS9-SF. Data were analyzed using MATLAB 8.5 (R2015a) and Statistical Parametric Mapping 12 (SPM 12) to evaluate brain activation. Results: This study found that IGD groups experience hyperactivation in the occipital and parietal lobes especially in the inferior occipital gyrus IOG and inferior parietal gyrus (IPG) but a hypoactivation on the frontal lobe. There a significant mean difference for the right IOG and left supplementary motor area (SMA) between the IGD and control groups at $p<0.025$ after, Bonferroni correction. A significant correlation was found ( $p<0.006$; Bonferroni correction) between cerebellum 45 right and stress behavior, $r=0.65$. Conclusion: These results indicated that individuals with IGD tend to have the rampant yet favorable ability in attention and recognition regulation but deterioration in reward processing. These findings provide a deeper understanding in developing appropriate guidelines and interventions to treat the Internet gaming addicts community, especially in the Malaysian population.
\end{abstract}

Keywords: Adolescents, internet gaming addiction, Stroop, Malaysia, video games

\section{INTRODUCTION}

A video game is an electronic game that players were the one to control images appears on the screen and involves the interplay between human and gaming interface on the device to allow a visual response. With internet access, players are able to stay connected with their virtual friends in the game system for an indefinite period of time. Meanwhile, the gaming industry evolved with the massive growth in the Malaysian population. Proven that, in 2019, 20.1 million Malaysian gamers have spent RM2 8 billion in the gaming industry and was classified as one of the remarkable economic growth in Southeast Asia. ${ }^{1}$ Generally, $88.7 \%$ of Internet users detected in Malaysia for 2020 and it remarkably predominates by individuals in their 20s. ${ }^{2}$ The regular Internet users in Malaysia increase dramatically in the year 2020 with half of the users spent 5 to 12 hours per day, compared to $37 \%$ of Internet

Address correspondence to: Dr. Mazlyfarina Mohamad (Ph.D), Centre for Diagnostic, Therapeutic and Investigative Studies, Faculty of Health Sciences, Universiti Kebangsaan Malaysia, Kuala Lumpur, Jalan Raja Muda Aziz, 50300 Kuala Lumpur, Malaysia. Tel: +60(11) 3935 2123, +60(3) 9289 7293, Email: mazlyfarina@ukm.edu.my

Date of Submission: 14 March 2021; Date of Acceptance: 2 June 2021

https://doi.org/10.54029/2021msd 
users in 2018. ${ }^{2}$ Subsequently, $7 \%$ of increment in 2020 for excessive Internet users (spent more than 12 hours) compared to $14 \%$ in 2018 . According to the Malaysian Communications and Multimedia Commission (MCMC), online gaming is considered as one of the major online activities in Malaysia when streaming the Internet as it increased $42.8 \%$ in 2020 from $35.2 \%$ in $2018^{2}$. While, majority of Malaysian Internet users utilized text communication (e.g. WhatsApp, WeChat, and Telegram) and other social networking platforms (e.g. Instagram, Twitter, Facebook, and YouTube) still topped the online activities with $98.1 \%$ and $93.3 \%$, respectively ${ }^{2}$.

Gaming can be very entertaining and through it, gamers can develop skills yet it also may result in one's getting too absorbed in video games regardless of any circumstances. ${ }^{3}$ This may evolve into an addiction form known as Internet gaming disorder (IGD) without even knowing about it. The World Health Organization (WHO) stated that IGD will be identified as a new mental disorder in the 11th Revision of the International Classification of Diseases (ICD11). ${ }^{4}$ Therefore, it requires vast attention from clinicians for preventions and also interventions. The criteria that proposed by American Psychiatric Association's Diagnostic and Statistical Manual of Mental Disorder (DSM-5) for IGD are preoccupation, engagement, jeopardized or giving up other activities (job, hobbies, relationship, study), tolerance, use game as escape place from reality and withdrawal. ${ }^{5}$ Previous studies disclosed that adolescents were more likely to develop IGD because they tend to take risky decisions behaviors as well to exhibit significant emotional reactivity compare to adults nor children. ${ }^{6-8}$ The factors of the adolescent vulnerability were external (e.g. peers influence) and internal (e.g. hormonal changes) environmental that promote their behavioral changes..$^{9}$ Nowadays, the youth generation is easily influenced by new surroundings or trends without proper guidance.

Cognitive flexibility is defined as the adaptation of human cognitive processing strategies to cope with unexpected changes or conditions. ${ }^{10}$ In other words, cognitive flexibility refers to the ability and adaptation in the process of reasoning when facing an unexpected situation or task or unfamiliar situation, then responding by thinking of combining various concepts creatively, and changing common knowledge or habits to produce a fresh and inventive conclusion or action. ${ }^{11-12}$ Individuals with high cognitive flexibility will tend to have the aptitude to be a fast learner, competent in solve problems creatively, and comfortably adaptable to new situations ${ }^{12}$. Disruptive attention control and cognitive behavior can increase the risk of experiencing IGD criteria through lack of action to suppress the urge to play the game in turn affecting the length of time spent playing. ${ }^{13-14}$ Meanwhile, a decrease in cognitive control on the motivational drive has the potential to contribute to the continuous involvement of online games. ${ }^{13}$

Benarous et al. stated that the severity regarding online game abuse was depending on the effect of compulsive Internet gaming behavior in interfering with a person's normal development which can be seen through various factors. ${ }^{15}$ For instance, in terms of biological factors (e.g.; the maturation of the brain's nervous system), cognitive factors (e.g.; emotional control, inhibition of motor circuit), psychological factors (e.g.; the emergence of adolescent identity, adolescent social role development), and also environmental factors (e.g., academic/career progress, social relationships). Besides, Ge et al. affirmed that extreme gamers and nicotine-dependence smokers shared alike neural mechanisms in impulsive inhibitions and cravings towards nicotine and games. ${ }^{16}$ Both researchers found that IGD has similar effects on neural activities with smokers and drug addicts. Bavelier et al. conveyed that attention controller components in regular gamers' brains tend to be less active during the challenging pattern task in fMRI study where it can be concluded that shooter gamers gave their attention completely and disregarded any unnecessary information more efficiently. ${ }^{17}$ On top of that, IGD demonstrates many similarities in physical and psychosocial manifestations with substance use disorder, including cerebral changes in the fMRI scanning 3 . This study involves the taskbased fMRI approach as Ko et al. revealed that a task-based fMRI (tb-fMRI) approach was the best way to appraise craving towards Internet-related activity including IGD.$^{18} \mathrm{He}$ believed that through the study of mechanism related to the desire of Internet addiction as a succor in development of neurobiological model of addiction and assist in future intervention processes. Moreover, the fMRI has similarities with an echo-planar imaging (EPI) techniques as it is more focused on cerebral cortex activation areas during the ongoing tasks in fMRI scanning and induced the increasing of neuronal metabolism less than $5 \%$ of total brain energy. ${ }^{19}$

Therefore, it raises a question on how does the pattern on neural activation of the human brain experiencing compulsive Internet gaming 
and its effect on human cognitive flexibility. As the IGD nor related subtypes of the Internet may still unnoticeable in Malaysia, so this study aimed was to investigate the neural activation involved in cognitive flexibility using the task-based fMRI that being triggered by the Stroop task among Malaysian young adults and its correlation with depression, anxiety, stress, and suicide issues. We hypothesized that an adolescent with IGD prone to experience a decline in brain activation areas that related to the regulatory mechanisms for executive control compared to healthy adolescents.

\section{METHODS}

This study was approved by the Institutional Ethics Committee (IEC) of Universiti Kebangsaan Malaysia (NN-2018-123). This study was conducted at the Department of Radiology, Universiti Kebangsaan Malaysia Medical Center (PPUKM), using a non-invasive functional magnetic resonance imaging (fMRI) of a 3.0 Tesla machine (Siemens Magneton Verio). Demographic data such as age, gender, daily use of the Internet per hour and the average hours of daily online game usage were included in this study. All participants have been explained and notified of the risks of the study before the scanning session began. Participants were required to sign an informed consent and completed psychological questionnaires as part of the screening process.

\section{Psychological assessments and screening process}

The subject screening process was carried out with an online form containing the questionnaire, IAT and IGD (Google LLC, Mento Park, California, USA) via google form The link has been distributed through the WhatsApp application (Facebook Inc., Mento Park, California, USA) and via email of the undergraduate student. Therefore, a total of 37 participants (IGD $=19$, Control $=18$ ) from the Faculty of Health Science of Universiti Kebangsaan Malaysia (UKM) were recruited in this study based on the inclusion and exclusion criteria below:

\section{Internet Addiction Test (IAT)}

IAT consists of 20 related items to measure the dependence and compulsive use of the Internet in an individual which assessed by a 5-point Likert scale. ${ }^{20-21}$ The criteria involved are the determination of Internet usage, tolerance, withdrawal symptoms, relapse, mood instability, and conflict. There are four range of severity of
Internet addiction: 1) 0 and 30 points (normal Internet users); 2) 31 and 49 (mild Internet users); 3) 50 to 79 (moderate Internet users); 4) 80 to 100 (uncontrolled \& excessive Internet users). As followed, according to Guan et al., the appropriate cut-off point to determine between the Internet and non-Internet dependency users among undergraduate students in Malaysia is $43 .^{22}$

\section{Internet Gaming Disorder Scale-Short Form} (IGDS9-SF)

IGDS9-SF is a psychometric tool containing nine core criteria for determining the severity of IGD by examining online and/or offline gaming activities over a 12 -month period. ${ }^{23}$ Among the criteria measured were preoccupied, withdrawal, tolerance, relapse, loss of interest, continuation, deception, escape, and negative impact towards relationships, education, or carrier. It should also be noted that the main purpose of this instrument is not to diagnose IGD but to assess its severity and negative effects on the life of the video player. The score range is between 9 to 45 marks where a higher score indicates a higher IGD level. As suggested by Pontes and Griffiths, distinguishing between players with IGD by repeating a "very frequent" response of five or more criteria out of nine criteria and playing online for more than two hours a day. ${ }^{23}$ Therefore, by following the proposed cut-off point for IGDS9-SF, this study has screened the participants based on the cut-off point of 21 out of $45 .{ }^{24}$

\section{Suicidal Behavioral Questionnaire-Revised (SBQ-R)}

SBQ- $R$ is a revised psychological instrument related to suicide issues in various dimensions such as 1) thoughts for lifetime suicidal ideation and/or suicide attempts, 2) frequency of suicidal ideation over the past 12 months, 3) threats of attempted suicide and 4) assess the tendency to commit suicide in the future. ${ }^{25}$ The total score ranges from 3 (no suicidal ideas or behavior) to 18 (very often suicidal ideas or behaviors). Whereas, the cut-off point for SBQ-R is 7 for the college or university student category as it considered as an adult public population.

\section{Depression Anxiety Stress Scales (DASS-21)}

DASS-21 is a clinical assessment for depression, anxiety and stress where each of the psychological symptoms consists of seven items with four answer scales to describe the symptoms that 
occurred during the previous week. ${ }^{26}$ The criteria measured in DASS-21 are 1) depression (anxiety, self-denial, lack of social interest and pleasure, self-deprecation, hopelessness), 2) anxiety (autonomous stimuli, anxiety according to situations, the tension on skeletal muscle and impacts of negative life events) and 3) stress (difficulty calming, nervous stimulation, irritable, agitated and impatience). The total scores for DASS for each mental disorder ranged from 0 to 42 . Severe pathological scores for the anxiety, depression, and stress domains were $28+, 20+$, and $34+$. The higher the score value, the worse the symptoms faced by the subject.

\section{Stroop Color Task \& MRI Acquisitions}

An event-related paradigm, the Stroop color task was applied in this study ${ }^{25}$. The paradigm was programmed in E-PRIME 2.0 (Psychological Software Tools, Inc., Sharpsburg, Philadelphia). There are three conditions/trials involved: 1) congruent; 2) incongruent; 3) neutral (control). This condition consists of four words related to color in Malay, namely "BIRU", "MERAH", "KUNING", "HIJAU", "XXXX" (control), and all these works were displayed in the center of the screen. Participants respond by referring to the color of the word displayed. This task will begin with a fixation exposure for 10 seconds then continued with neutral $>$ congruent $>$ incongruent, in which each condition was separated by 16 seconds of fixation display (refer to Figure 1).

The acquisition parameters for tb-fMRI as follows: repetition time $(\mathrm{TR})=2000 \mathrm{~ms}$, echo time $(\mathrm{TE})=30 \mathrm{~ms}$, flip angle $=90^{\circ}$, field of view $(\mathrm{FOV})=220 \times 220$, matrix size $=64 \times 64$, interleaved sequence: 33 slices per volume. For anatomical imaging, 3D T1-weighted sagittal scan was acquired for anatomical references with EPI data were collected with the following parameters: $\mathrm{TR}=2530 \mathrm{~ms}, \mathrm{TE}=3.39 \mathrm{~ms}, \mathrm{~T} 1=1100 \mathrm{~ms}$, $\mathrm{FOV}=256 \times 256 \mathrm{~mm}^{2}$, slices $=144$, voxel size $=1.0 \times 1.0 \times 1.3 \mathrm{~mm}^{2}$, flip angle $=7^{\circ} .{ }^{27}$

\section{Pre-processing analysis and Area of Interest (ROI) determination}

Data were analyzed using MATLAB 9.3 version of R2017b (MathWorks Inc., MA, USA; https://www.mathworks.com/products/matlab), Statistical Parametric Mapping 12 (SPM12) package (Functional Imaging Laboratory, Wellcome Department of Imaging Neuroscience Institute of Neurology, University College of London, UK; https://www.fil.ion.ucl.ac.uk/spm/ software/spm12). Therefore, the workflow in SPM12 is divided into three main components namely; 1) Pre-processing of fMRI data, 2) Statistic model speciation and 3) Statistical inference. The pre-processing phase was divided into temporal and spatial processing. Temporal processing only involves a slice timing process, while, space processing consists of realignment, co-registration, normalization, and smoothing. To improve the signal-to-noise ratio, the quality screening was performed during pre-preprocessing by filtering out the raw data that exceeding $3^{\circ} \mathrm{mm}$ or $2^{\circ}$ of translation and rotation movements as well for baseline position differences on functional and $\mathrm{T} 1$ weighted images on before and after normalized images. For model specification, this study applied the flexible factorial by referring to the model prepared by Gläscher \& Gitelman for contrast weights for the Stroop color task with threshold at $\mathrm{p}<0.05$, family-wise error rate (FEW).$^{28}$ This model consists of two groups of subjects (IGD and control) and has more than three conditions; 1) Neutral, 2) Congruent, and 3 Incongruent. The contrast weight for the main effect ("Main Effect") is influenced by the number of subjects for each group. For retrieved image visualization, the xjView 4 version 8.14 (https:// www.alivelearn.net/xjview/2 was applied in this study, whereas, the Wfu-PickAtlas 3 toolbox were used to produce the best quality of ROI masks results (ANSIR Laboratory, School of Medicine, Wake Forest University, North Carolina, USA, https://www.nitrc.org/projects/wfu_pickatlas/).

The brain areas stimulated by the Stroop color task were selected to be evaluated for the regionof-interest (ROI) analysis. ROI is represented by voxels for areas of the brain that exhibit the highest magnetic resonance signal within a $5 \mathrm{~mm}$ radius centered at the appropriate MNI coordination ${ }^{18}$. This step was performed by the toolbox, MarsBar (MARSeille Boîte À Région d'Intérêt) version 0.44 (http://marsbar.sourceforge.net/), to extract the BOLD signal contrast and displayed a range of percentage for activation strength on ROI ${ }^{29}$ The contrast was involved clusters of the voxel that significantly at a cluster-level threshold, $\mathrm{p}<$ 0.05 , FWE (family-wise error) correction.

\section{Statistical analysis}

All descriptive statistical analyses were performed using SPSS Statistics 23.0 for Windows (SPSS Inc., Chicago, IL, USA; https://www.ibm.com/ my-en/products/spss-statistics). In this study, a Bonferroni correction method was applied 
for mean differences and correlation analysis, thus, the p-value varies for each group. First, to compare the mean difference in activation of BOLD signals between IGD and control group, so a two-sample t-test was performed. Next, a correlation analysis was performed to identify the association between the brain activation BOLD signals with psychological assessment variables such as depression, anxiety, stress and suicide. The values of analysis taken by considering the normality of each variable involved before proceeding with the next test.

\section{RESULTS}

Sociodemographic data and psychological assessment

As shown in Table 1, the mean of IAT in the IGD group was $65.32(\mathrm{SD}=12.03)$ and showed very frequent use of the Internet as a daily activity and often experienced various disorders/problems caused by the Internet. It was found that $84 \%$ of the total IGD group experienced high Internet addiction with four percent of the percentage being compulsive Internet users at a severe level while the rest at moderate levels. Compared to the IGD group, the control group was more likely to experience mild levels (mean $\pm \mathrm{SD}=45.16 \pm 11.86$ ). The significant mean difference at $\mathrm{p}<0.001$ for IAT scores between the two groups confirmed that the IGD group in this study was highly dependent on the Internet in their daily lives compared to the control group. The IGD group (mean $\pm \mathrm{SD}=$ $28.12 \pm 5.43$ ) showed a high level of dependence on online games compared to the control group (mean $\pm \mathrm{SD}=11.28 \pm 2.39)$. There was a significant difference in IGDS9-SF scores between the IGD group and the control, $\mathrm{p}<0.001$. This indicates that the IGD group has a high susceptibility to online gaming. However, there was no difference in the mean of SBQ-R score between both groups. In addition, the average score for the IGD group showed that they experienced a moderate symptom of depression and stress. The control group obtained normal scores for the stress domain and moderate for depression. However, according to the DASS-21 scoring, the IGD group experienced severe symptoms of anxiety while the control group in the intermediate level. Nevertheless, there was no difference in the mean score for all DASS-21 domains between the IGD and control groups. There were no significant differences in the age, DASS-21 and SBQ-R scores between the two groups $(p>0.05)$. A significant intergroup difference was observed in scores of IAT and IGDS9-SF as shown in Table 1.

Table 2 showed that SBQ-R produced a weak but positive correlation between DASS-21 domains, depression $(\mathrm{r}(50)=0.49, \mathrm{p}<0.01)$, anxiety $(\mathrm{r}(50)=0.38, \mathrm{p}<0.01)$ and stress ( $\mathrm{r}(50)$ $=0.33, \mathrm{p}<0.05)$. No significant relationship was found between depression, anxiety, stress and suicide with IAT and IGD for the population in this study. Therefore, this study also found that the psychological assessment for IGD and IAD had a strong correlation $\mathrm{r}=0.60(\mathrm{p}<0.01)$.

\section{Behavioral results of the Stroop Task}

The subject's behavior throughout the Stroop color task taking into account the percentage of correct

Table 1: The mean and standard deviation of demographic and psychological assessment

\begin{tabular}{lccc}
\hline \multirow{2}{*}{ Variables } & IGD $(\mathbf{N}=\mathbf{1 9})$ & Control $(\mathbf{N}=\mathbf{1 8})$ & \multirow{2}{*}{ p value } \\
\cline { 2 - 3 } Gender & Mean \pm SD & Mean \pm SD & \\
(Male/Female) & $65.21 \pm 12.41 / 65.45 \pm 12.14$ & $43.00 \pm 8.88 / 47.91 \pm 14.83$ & 0.002 \\
Age (Years) & $22.64 \pm 1.19$ & $22.80 \pm 1.19$ & $<0.001^{*}$ \\
IAT & $65.32 \pm 12.03$ & $45.16 \pm 11.86$ & $<0.001^{*}$ \\
IGDS9-SF & $28.12 \pm 5.43$ & $11.28 \pm 2.39$ & 0.45 \\
DASS-21 & & & 0.11 \\
$\quad$ Depression & $13.52 \pm 9.08$ & $11.20 \pm 12.04$ & 0.06 \\
$\quad$ Anxiety & $15.44 \pm 7.38$ & $11.60 \pm 9.38$ & 0.85 \\
$\quad$ Stress & $17.92 \pm 8.36$ & $13.12 \pm 9.19$ & \\
SBQ-R & $5.08 \pm 3.28$ & $4.92 \pm 2.84$ & \\
\hline
\end{tabular}

*significant, $\mathrm{p}<0.001$

Two sample t-test and chi-square were performed to evaluate the group difference in continuous and categorical variables respectively.

Abbreviation: $\mathrm{SD}=$ Standard Deviation 
Table 2: The correlation between psychological assessments

\begin{tabular}{|c|c|c|c|c|c|}
\hline \multirow{2}{*}{ Correlation (r) } & \multirow{2}{*}{ IGD } & \multicolumn{3}{|c|}{ DASS-21 } & \multirow{2}{*}{$\begin{array}{l}\text { SBQ-R } \\
\text { Suicide }\end{array}$} \\
\hline & & Depression & Anxiety & Stress & \\
\hline IAT & $0.60 * *$ & 0.77 & 0.14 & 0.15 & 0.09 \\
\hline IGD & & -0.02 & 0.14 & 0.12 & -0.06 \\
\hline \multicolumn{6}{|l|}{ DASS-21 } \\
\hline Depression & & & $0.79 * *$ & $0.79 * *$ & $0.49 * *$ \\
\hline Anxiety & & & & $0.76 * *$ & $0.38 * *$ \\
\hline Stress & & & & & $0.33 *$ \\
\hline
\end{tabular}

**Correlation is significant at the level of 0.01 (2-tailed)

*Correlation is significant at the level of 0.05 (2-tailed)

answers as well as the average time required to respond to each trial (neutral, congruent, incongruent). As shown in Table 3, the control group performed better than the IGD group for this task with the highest accuracy and rapid reaction time. For the neutral experiment, the control group $(\bar{x}=80.60 \% ; \mathrm{SD}=10.45)$ led $4.32 \%$ of the IGD group $(\bar{x}=76.28 \%$; $\mathrm{SD}=13.08)$. The control group had an average percentage of correct answers, $\bar{x}=83.85 \%(S D=9.23$ ) for congruent and $\overline{\mathrm{x}}=59.38 \%(\mathrm{SD}=13.16)$ for incongruent trials. Ahead of the IGD group, $\bar{x}=81.96 \%$ $(\mathrm{SD}=11.73)$. For the percentage of correct answer accuracy for the congruent and incongruent trials for the IGD group, it was $\overline{\mathrm{x}}=81.96 \%$ $(\mathrm{SD}=11.73)$ and $\overline{\mathrm{x}}=54.72 \%(\mathrm{SD}=18.29)$, respectively. However, the IGD group exhibited a decline in the percentage of accuracy rate. It manifests that the IGD group has confronted difficulty in answering incongruent trials, in contrast to the control group. There are no significant differences ( $p>0.05$ ) were found for the accuracy rate percentage and average reaction rate for all trials involved between both groups.

\section{Brain activation area for IGD and control group}

There are activation of the occipital, parietal and frontal lobes in the IGD group that is stimulated in this task. Areas involved in the activation of the IGD group are the inferior occipital gyrus (IOG), inferior parietal gyrus (IPG), supplementary motor area cortex (SMA), the dorsal striatum (caudate \& putamen) and inferior frontal gyrus triangularis (IFGTri) (refer Table 4). Meanwhile, the activation of the control group is IOG, postcentral, precentral, middle occipital gyrus (MOG), SMA, cerebellum and insula. Each voxel activation of the BOLD signal was filtered using an effective family-wise error (FWE) rate at $p$ $<0.05$. Both hemispheres in the IOG involved, of which the left hemisphere $(-30,-88,-4)$ is the area with the broad activation area at 30267 voxels $(t=11.19)$. Meanwhile, the right IOG (27, -94 , $-4)$ of the IGD group was significantly activated at peak $\mathrm{T}$ value, $\mathrm{t}=13.60$ encompass with 393 voxels. There is a similarity with the IGD group, where this task also stimulating high activation in the right IOG $(24,-91,-1)$ in the control group, by having the highest maximum intensity voxel of 365 voxels involved at $t=14.61$.

Table 3: The accuracy rate and reaction time of Stroop task between IGD and control group

\begin{tabular}{llccc}
\hline Trials & Variables & \multicolumn{2}{c}{ Mean \pm SD } & \multirow{2}{*}{ p value } \\
\cline { 3 - 4 } & & IGD $(\mathbf{N}=\mathbf{2 2})$ & Control $(\mathbf{N}=\mathbf{2 4})$ & \\
\hline Neutral & Accuracy rate (\%) & $76.28 \pm(13.08)$ & $80.60 \pm(10.45)$ & 0.74 \\
& Reaction time (ms) & $0.78 \pm(0.13)$ & $0.80 \pm(0.12)$ & 0.74 \\
Congruent & Accuracy rate (\%) & $81.96 \pm(11.73)$ & $83.85 \pm(9.23)$ & 0.55 \\
& Reaction time (ms) & $0.71 \pm(0.15)$ & $0.73 \pm(0.12)$ & 0.58 \\
Incongruent & Accuracy rate (\%) & $54.72 \pm(18.29)$ & $59.38 \pm(13.16)$ & 0.32 \\
& Reaction time (ms) & $2.57 \pm(8.50)$ & $0.80 \pm(0.16)$ & 0.34
\end{tabular}

Abbreviation $: \mathrm{ms}=$ Milliseconds, $\mathrm{SD}=$ Standard Deviation 
Table 4: List of active brain areas activated by Stroop color task according group with the magnitude of activation (peak $T$ value and cluster voxels) and their respective coordinates

\begin{tabular}{|c|c|c|c|c|c|c|}
\hline \multirow{2}{*}{ Peak MNI region } & \multirow[b]{2}{*}{ Hemisphere } & \multirow{2}{*}{ Cluster voxels } & \multirow{2}{*}{$\begin{array}{c}\text { Peak T } \\
\text { value }\end{array}$} & \multicolumn{3}{|c|}{ Peak MNI coordinate $(\mathrm{mm})$} \\
\hline & & & & $\mathbf{X}$ & $\mathbf{Y}$ & $\mathbf{Z}$ \\
\hline \multicolumn{7}{|l|}{ IGD group } \\
\hline \multirow{2}{*}{ IOG } & $\mathrm{R}$ & 393 & 13.60 & 27 & -94 & -4 \\
\hline & $\mathrm{L}$ & 30267 & 11.19 & -30 & -88 & -4 \\
\hline \multirow{2}{*}{ IPG } & $\mathrm{L}$ & 1565 & 11.09 & -45 & -28 & 44 \\
\hline & $\mathrm{R}$ & 1310 & 10.31 & 36 & -46 & 53 \\
\hline SMA & $\mathrm{L}$ & 252 & 9.51 & -3 & 8 & 50 \\
\hline Caudate & $\mathrm{L}$ & 11 & 5.71 & -18 & -4 & 17 \\
\hline Putamen & $\mathrm{L}$ & 9 & 5.41 & -24 & -1 & 2 \\
\hline Caudate & $\mathrm{R}$ & 8 & 5.32 & 21 & -4 & 14 \\
\hline IFGTri & $\mathrm{L}$ & 12 & 5.27 & -33 & 23 & 20 \\
\hline \multicolumn{7}{|l|}{ Control group } \\
\hline $\mathrm{IOG}$ & $\mathrm{R}$ & 365 & 14.61 & 24 & -91 & -1 \\
\hline Postcentral & $\mathrm{L}$ & 1074 & 11.85 & -42 & -31 & 41 \\
\hline MOG & $\mathrm{L}$ & 371 & 11.63 & -18 & -97 & -1 \\
\hline SMA & $\mathrm{L}$ & 164 & 10.44 & -3 & 5 & 53 \\
\hline Precentral & $\mathrm{L}$ & 148 & 10.32 & -54 & 8 & 32 \\
\hline Postcentral & $\mathrm{R}$ & 643 & 9.68 & 54 & -16 & 44 \\
\hline Precentral & $\mathrm{R}$ & 28 & 5.77 & 54 & 5 & 38 \\
\hline Cerebellum 45 & $\mathrm{R}$ & 6 & 5.71 & 27 & -46 & -22 \\
\hline Insula & $\mathrm{L}$ & 5 & 5.13 & -30 & 17 & 5 \\
\hline
\end{tabular}

\section{IGD vs Control}

Control vs IGD

No significant activation occurred at FWE (0.05)

No significant activation occurred at FWE (0.05)

Differences (IGD vs. Control) Incongruent

\begin{tabular}{lllllll} 
IPG & $\mathrm{R}$ & 1 & 5.09 & 36 & -49 & 53 \\
\hline
\end{tabular}

$* p<0.05(F W E)$

Abbreviation: $\mathrm{MNI}=$ Montreal Neurological Institutes, $\mathrm{R}=$ Right Hemisphere, $\mathrm{L}=$ Left Hemisphere, $\mathrm{IOG}=\mathrm{Inferior}$ Occipital Gyrus, IPG = Inferior Parietal Gyrus, SMA = Supplementary Motor Area, IFGTri = Inferior Frontal Gyrus Triangularis, $\mathrm{MOG}=$ Middle Occipital Gyrus

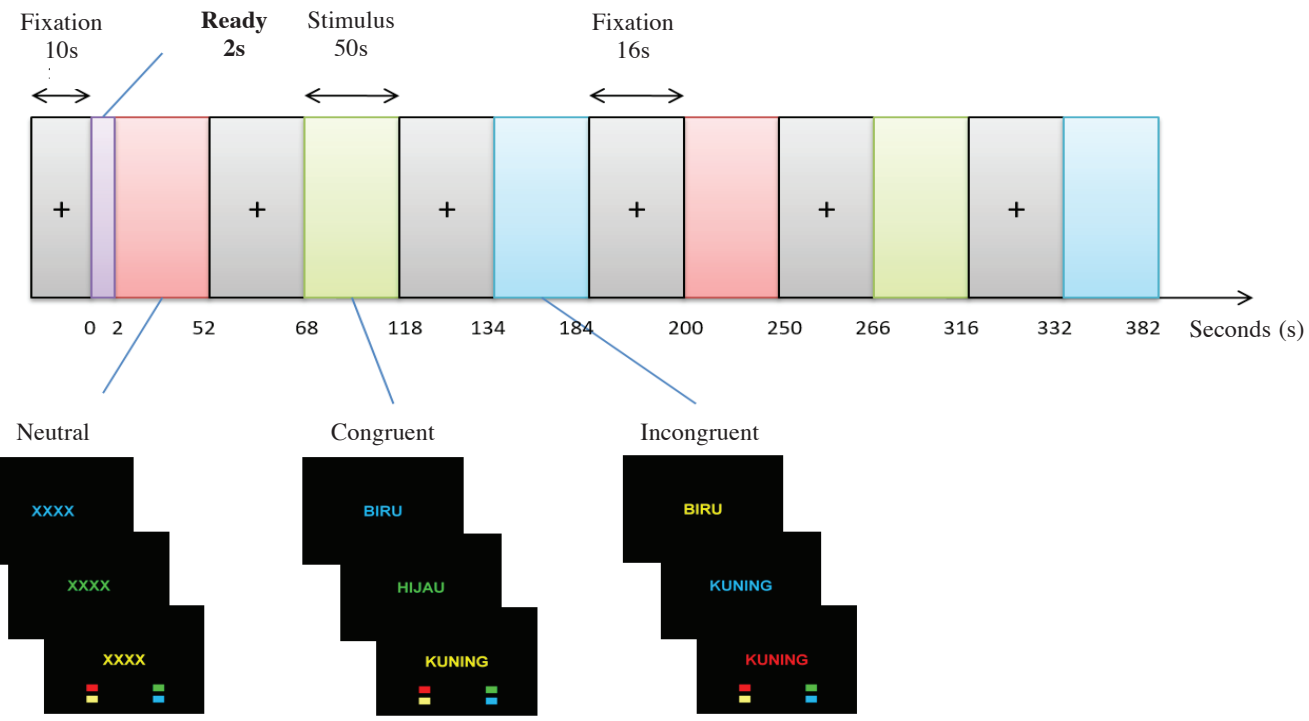

Figure 1. Flow work of Stroop color paradigm during tb-fMRI scanning. 


\section{DISCUSSIONS}

The Internet is a major platform that integrates various Internet-related activities, including accessing online games. As a result of this, compulsively recorded Internet users can spend three times more than regular users with an average total of 5 hours 30 minutes per day and 38.5 hours per week compared to the average for average users of only 4.9 hours per week. ${ }^{30-31}$ This study found that the psychological assessment for IGD and IAD had a strong correlation at $\mathrm{p}<0.01$. This result was congruous with the study of Griffiths and Király et al. showed a positive correlation between Internet addiction disorder (IAD) and IGD, both disorders have more common in terms of variables involved (e.g. preoccupation, conflict, withdrawal symptoms, mood instability and repetition) ${ }^{32-33}$ Nevertheless, Király et al. asserted that there are still differences in terms of conceptual behavioral classification in IGD which each have diagnostic criteria that separate the similarities to classify IAD or IGD.$^{33}$ These criteria focus on the behavior or response of individuals when faced with interference because the main purpose of using the Internet is to play online games also contributes to the differences between IGD and IAD.

Meanwhile, adolescents are most affected by IADs because they have been exposed to the Internet at a young age which caused them to be highly dependent and intolerant of frustration with the Internet. ${ }^{34}$ Undoubtedly, this study targeting adolescents by having the age range of the participants was 22 years. Even so, researcher reported that most youths unconscious that they were addicted and more dependent on Internet usage in everyday life. ${ }^{35}$ This situation is due to the fact that university students rely entirely on the Internet to complete assignments, acquire course-related information, share knowledge and even build new ideas in group projects to achieve a better future. ${ }^{36}$ In addition, the female student's involvement was higher than male students with differences of $24 \%$ because the female students' population was higher than the male students in the two faculties involved. However, this study found that the IGD group was more dominated by male students (56\%) than the control group (20\%). This outcome was similar to Lee et al. which, their study found that males are likely to be addicted to online games compared to females in terms of gender comparison of IGD. ${ }^{37}$ As consistently to $\mathrm{Li}$ and Wang's research in which $47.5 \%$ of Chinese males had a greater chance of developing online game addiction than females. ${ }^{38}$ Besides, Spekman et al. reported that companies use online/video game market strategies with more focus on their sales that are specially designed to target male customers to increase sales. ${ }^{39}$ Therefore, it is not surprising that online gaming users' are higher among men and their vulnerability to IGD increases. Porter et al. stated that IGD is conceptualized as the use of compulsive online/ video games which if individuals play excessive video games that can result in preoccupation and loss of control over the video games, leading to various negative psychological and/or physical effects. ${ }^{40}$

In terms of participant's behavior during the Stroop task, the control group performed better than the IGD group for this task with the highest accuracy and rapid reaction time. However, the IGD group exhibited a decline in the percentage of accuracy rate. It manifests that the IGD group has confronted difficulty in answering incongruent trials, in contrast to the control group. There are no significant differences ( $>0.05$ ) were found for the accuracy rate percentage and average reaction rate for all trials involved between both groups. Concurrently, these results are similar to the several previous studies ${ }^{27,41-43}$. In their study, it was revealed that the subjects classified in the IGD group tends to exhibited difficulty in the Stroop color task with a high percentage of error rates and needed a longer time to react to stimuli, especially on incongruent stimuli. Additionally, multiple of study by have agreed that cognitive control in an individual with IGD had deteriorated in remark of the frequency errors rate in an incongruent trial in the Stroop color task..$^{41,44-45}$ Thus, IGD subjects tend to exhibit changes in the connectivity of executive control functions and visual networks related to attention bias.

From brain activation results, it can be concluded that the stimulus in the Stroop color task has stimulated high activation of the IOG, especially peaked on the right hemisphere. Both groups had activation on the IOG, however, the IGD group experienced hyperactivation on the IOG compared to the hypoactivation of the right IOG in the control group. Activation in IOG is induced due to the process of stimulus recognition by focusing on procurable forms or patterns. ${ }^{46-47}$ The IOG is mostly activated on IGD subjects probably because in-game culture, especially MMORPGs, players have the opportunity to personalize their own avatars (graphic agents representing players in the game), remembering and recognize during play and the routines will 
Table 5: Mean difference for BOLD signal between IGD and control group

\begin{tabular}{|c|c|c|c|c|c|c|c|}
\hline \multirow[t]{2}{*}{ Regions } & \multicolumn{2}{|c|}{$\begin{array}{c}\text { IGD } \\
(\mathrm{N}=19)\end{array}$} & \multicolumn{2}{|c|}{$\begin{array}{l}\text { Control } \\
(N=18)\end{array}$} & \multirow[t]{2}{*}{$\mathbf{t}$} & \multirow[t]{2}{*}{ df } & \multirow[t]{2}{*}{ p value } \\
\hline & Mean & S.D. & Mean & S.D. & & & \\
\hline IOG (R) & 0.36 & 0.08 & 0.30 & 0.03 & 3.16 & 35.00 & $0.003 *$ \\
\hline SMA (L) & 0.14 & 0.04 & 0.21 & 0.01 & -6.02 & 35.00 & $0.000^{*}$ \\
\hline
\end{tabular}

$* \mathrm{p}<0.025$, Abbreviation: BOLD = Blood-oxygen-level dependent, S.D = Standard Deviation, R = Right Hemisphere, L = Left Hemisphere, IOG = Inferior Occipital Gyrus, SMA = Supplementary Motor Area

continue until they change the characteristics of the avatar. Thus, IGD individuals tend to consume a higher recognition process than control groups. The mean difference analysis in this study has applied Bonferroni correction and its revealed a significant difference in blood-oxygen-leveldependent (BOLD) signal change for right IOG and left SMA between the IGD and control groups at $\mathrm{p}<0.025$ as shown in Table 5 .
Simultaneously, the results of Dong et al. found a reduction in brain activity in the frontal lobe where it showed a decrease in cognitive control efficiency during the Stroop task. ${ }^{48}$ Likewise, this study also confronted a decline in brain activity in the frontal lobe where it only triggered the left inferior frontal gyrus triangularis (IFGTri) with the lowest magnitude of activation in the IGD group at $t=5.27$. Meanwhile, researchers

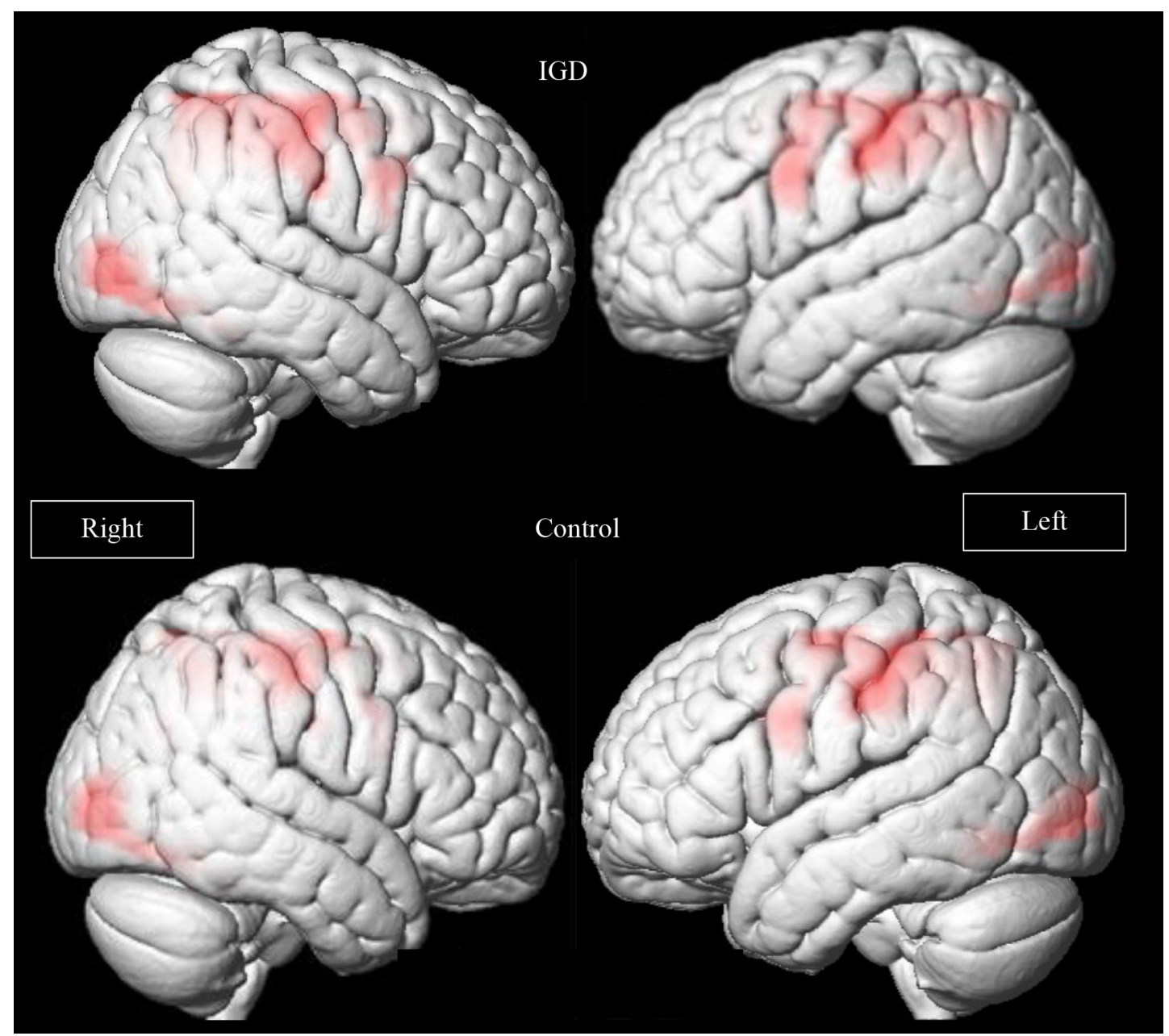

Figure 2. Comparison of activation that occurred between IGD groups and controls using family-following error correction (FWE), p $<0.05$. 
also found hyperactivation in the middle frontal gyrus (MFG), anterior cingulate cortex (ACC) and limbic systems in which these areas are involved in executive control functionality. ${ }^{49}$ Dong et al . found an increase in activation in the corticostriatal of IGD subjects in processing a winning reward and also increase activity in frontal gyrus while processing the losing reward during the guessing task. ${ }^{50}$ It shows IGD subjects show a deterioration in executive control and reward processing. The executive network (EN) involving dorsolateral prefrontal cortex (DLPFC) and the parietal cortex which both play an important role in manipulating information of working memory, problem-solving and as a source of attention in adaptive behavior. ${ }^{51-52}$

The IGD group in this study exhibited a high magnitude of brain activations in IPG for both hemispheres while there was no IPG activation within the control group. These findings concur with the study of Leménager et al. and Zhang et al. have similarities in which IGD subjects tend to manifest a hyperactivation of inferior parietal lobules. ${ }^{27,53}$ The IPG activation was triggered due to its involvement in attention regulation to allow an individual to remain focusing on the characteristics of the stimulus and be able to be more prepared when facing more difficult stimuli..$^{54}$ In other words, activation in IPG triggered during attention-shift events as the attention reflexively shifted towards the important stimulus features and it's also involved in semantic processing..$^{55-56}$ In this study, subjects had to perform a simple cognitive task by matching words with colors (simple trials = neutral and congruent) while giving the correct response but the attention-shift was interrupted by incongruent trials which are more complex and require more concentration before giving a response. Furthermore, this study also found a significant activation difference (FWE, p <0.05) in the right IPG between the IGD group and control group when confronting with incongruent trials. Thus, it is likely that IGD subjects experience more conflict in cognitive control and require more attention during this task. $^{57}$

Activation of the dorsal striatum also plays an important role in cognitive control where increased brain activity in caudate in cognitive control disorders in IGD. This can be proved through the study of Dong et al. and Yuan et al. showed that an increase in the magnitude of activation at higher doses was associated with higher rates of fault on incongruent stimuli by IGD individuals. ${ }^{41}$, ${ }^{58}$ Ultimately, IGD individuals are more likely to exhibit a decline in cognitive control. Furthermore, Zhang et al found an increase in activity in the IPG, middle occipital gyrus and dorsolateral prefrontal cortex (DLPFC) when confronted with Stroop color tasks containing online-based stimuli. ${ }^{27}$ Those areas are believed to be involved in visual processing, cognitive control, selective

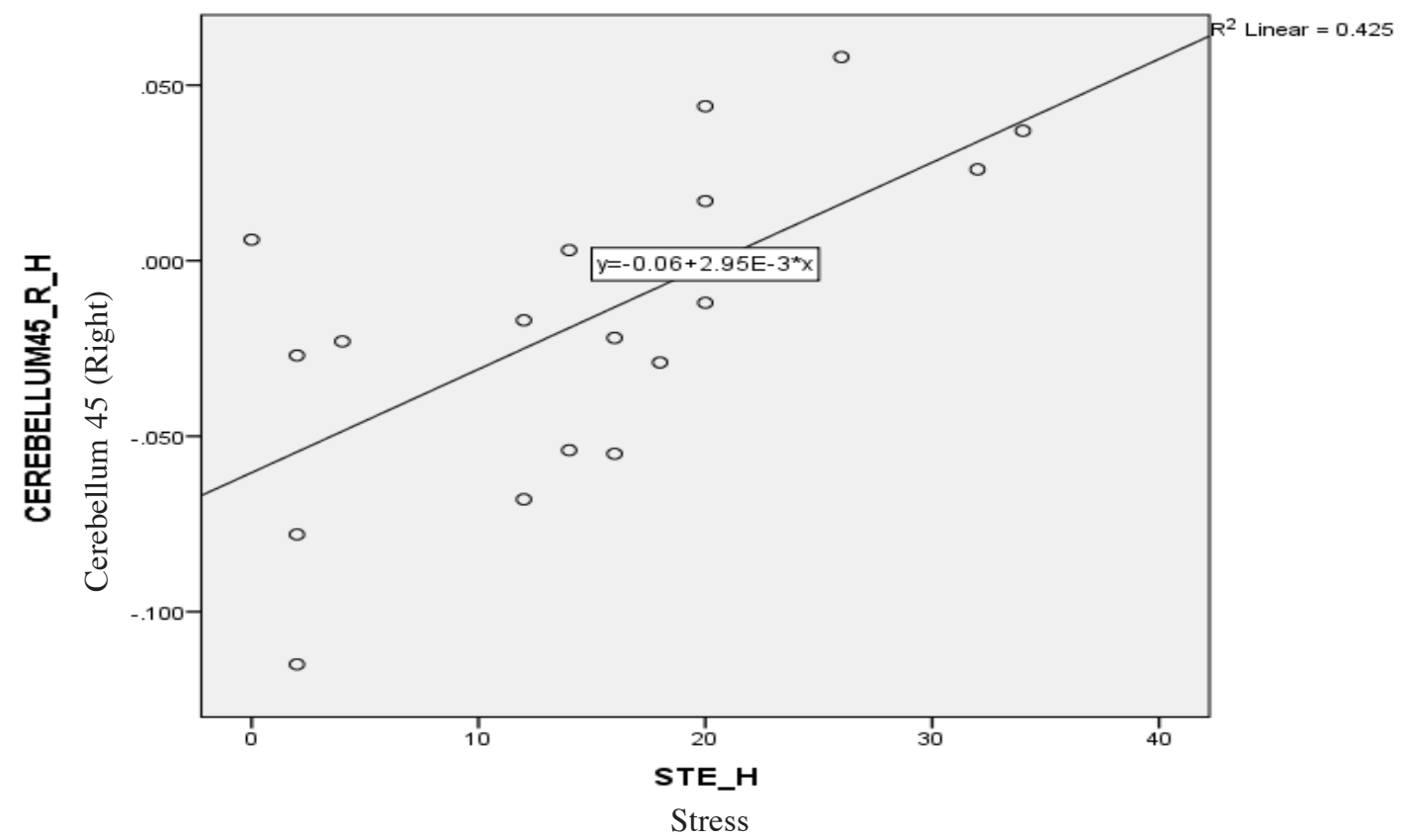

Figure 3. The strong correlation between cerebellum 45 and stress, $r=0.65(p<0.006)$ within control group. 
observation and memory processing. Through these results, Zhang et al. also concluded that IGD subjects showed a degeneration in visual and cognitive abilities while dealing with online gamebased words.$^{27}$ Meanwhile, the study of Dong et al. examined RGU participants ("Recreational Game Use") had a better cognitive control as well as greater activation of brain areas involved in motivation during reward processing compared to IGD participants. ${ }^{50}$ It is because RGU was more motivated in winning situations than losing situations for online games. This condition is an impetus for RGU individuals to limit and prevent cravings and control online games so as not to go towards IGD because their cognitive abilities are still acting normally.

\section{Correlation of BOLD signal change with variables involved in psychological assessment}

The results of correlation analysis found a significant and positive relationship ( $\mathrm{p}<0.006$; $\mathrm{r}=0.65$ ) on cerebellum 45 right with stress behavior, in control group. In general, the cerebellum functions in a voluntary movement, coordinate body balancing and motor regulation. ${ }^{59}$ The cerebellum is also capable of performing in cognitive control such as attention, sensory processing, work memory and emotional responses such as fear or satisfaction. ${ }^{60-62}$ Meanwhile, the function of the cerebellum in controlling emotions is supported by adjacent limbic regions such as the amygdala, the nucleus accumbens and the hippocampus. ${ }^{63-64}$ Furthermore, a recent systematic review by Moreno-Rius also stated that the cerebellum is strongly associated with stress disorders as it is linked to a network of related brain areas such as the amygdala, hypothalamus, hippocampus and also prefrontal cortex (PFC), which all those regions responsible as an intermediate system to influence stressrelated neurochemical processes. ${ }^{65}$ Nonetheless, there is no significant correlation between BOLD signal changes of IGD group with depression, anxiety, stress and suicide. This is due to the smaller sample size, either the IGD nor control group, which obstruct this research from getting a piece of correlation evidence.

However, this study unable to unfolds all the underlying aspects that equivalent to IGD. This was due to the limited number of sample as well as the unequal gender distribution. Therefore, it is recommended for future research to consider this limitation by including larger sample sizes with the number of men and women consistent with age limit variation. Several improvements can be made by the future researcher to produce better quality results. These results could not be generalized to a larger population as it only involved a small number of participants. However, the number of participants selected is based on the calculation of sample size appropriate to the study site. Subsequent studies should take the initiative to recruit more subjects with more male to female ratios or conduct studies with only participation from males. This is due to the fact that the percentage of male playing online games is higher than women..$^{6-69}$

Apart of that, we acknowledged that there were another comorbid disorder correlates with IGD, other than those included in this study, especially attention-deficit hyperactivity disorder (ADHD) among youth in Malaysia. ADHD is a developmental disorder characterized by hyperactivity, impulsivity and inattention, with common correlates such as depressive, dejection, surge of agitation and executive inflexibility. ${ }^{70-73}$ Nonetheless, with the number of sample available in for this study it was inadequate to accommodate the ADHD as a parameter along with other disorders (depression, anxiety, stress, suicidal behaviors). This can be done by further investigating the relationship of other comorbid disorders with Internet addiction by considering other types of Internet addiction (online gaming, gambling, cyber, social networking) that may affect consumer lifestyle. Therefore, the academic and research community should continuously conduct relevant studies to solve this problem so that authentic data can be used to help the government to generate Internet usage policies. Lastly, future research should consider to analyzing and evaluating the positive contributions and benefits that online gaming offers towards the gamers as believed there are advantages to be gained through it if consume in moderation usage.

In conclusion, this study found that IGD groups experience hyper-activation in the occipital and parietal lobes especially in the IOG and IPG aroused by the Stroop color task. This demonstrated that individuals with IGD tend to have the rampant yet favorable ability in attention and recognition regulation than healthy individuals. In contrast, the IGD group experienced hypoactivation on the frontal lobe. It showed that IGD subjects experienced executive control and reward processing deterioration. There was a significant and positive relationship on cerebellum 45 right with stress disorder, $\mathrm{r}=0.65$. 
These findings provide preliminary exposure related to the functioning of the human brain while playing online games and expand knowledge related to Internet addiction and online games that are occurring among Malaysian youth. Furthermore, it can provide a deeper understanding in developing guidelines and policies for the use of the Internet to treat the community of Internet game addicts, especially the people of Malaysia. The Internet has become a staple widget for every individual as we were completely dependent on it to survive in this technology modern life. This act result indirectly in an individual becoming addicted to online-based activities as the Internet works as a platform for browsing online. However, self-restraint, strict time management, and engaging in sports or volunteer activities are some of the small steps that can be taken to limit daily use of the Internet, especially online games.

\section{ACKNOWLEDGMENT}

This study was fully sponsored by a grant (GGP2017-080) from the UKM Research Management and Instrumentation Center. Meanwhile, E-PRIME software (Psychological Software Tools, Inc., Sharpsburg, Philadelphia) was sponsored by a Research University Grant (GUP-2015-043). We would like so express our gratitude to Head of Radiology Department, Universiti Kebangsaan Malaysia Medical Center (PPUKM), for allowing us to use MRI machine until the completion of data collection using a non-invasive functional magnetic resonance imaging (fMRI) of a 3.0 Tesla machine (Siemens Magneton Verio). Very special thanks to Encik Mohamad Nor Affendy Bin Awang and Puan Nooradila Binti Zolkiflee as our radiographers that assisted us throughout this research with their fMRI scanning techniques.

\section{DISCLOSURE}

Financial support: This study is fully sponsored by a grant (GGP-2017-080) from the UKM Research and Instrumentation Management Center. Meanwhile, E-PRIME software (Psychological Software Tools, Inc., Sharpsburg, Philadelphia) has been sponsored by the Research University Grant (GUP-2015-04).

\section{Conflicts of interest: None}

\section{REFERENCES}

1. Elliot R. Insights into Malaysia's games market and its gamers [Internet]. Amsterdam, Netherlands: Newzoo; 2020 Jan-[cited 2020 Oct 11]. Available from https://newzoo.com/insights/articles/insightsinto-malaysias-games-market-and-its-gamers/

2. Malaysian Communications and Multimedia Commission (MCMC). Internet users surveys 2020. Cyberjaya, Malaysia: Malaysian Communications and Multimedia Commission (MCMC); 2020 Dec:1160.

3. Chen KH, Oliffe JL, Kelly MT. Internet gaming disorder: An emergent health issue for men. Am J Men's Health 2018; 1-9.

4. World Health Organization (WHO). Addictive behaviours: Gaming disorder. Geneva, Switzerland: World Health Organization; 2018 Sept.

5. American Psychological Association (APA). Internet Gaming Disorder Diagnostic and Statistical Manual of Mental Disorders: DSM-V, 5th ed. Washington, DC: American Psychological Association; 2013.

6. Steinberg L. Cognitive and affective development in adolescence. TRENDS in Cognitive Science 2005; 9(2): 69-74.

7. Casey BJ, Jones RM, Hare TA. The adolescent brain. Ann N Y Acad Sci 2008; 1124: 111-26.

8. Kaess M, Ghinea D, Fischer-Waldschmidt G, Resch F. The outpatient clinic for adolescent risk-taking and self-harm behaviors (AtR!Sk) - A pioneering approach for outpatient early detection and intervention of borderline personality disorders. Prax Kinderpsychol Kinderpsychiatr 2017; 66(6): 404-22.

9. Jaworska N, MacQueen G. Adolescence as a unique developmental period. J Psychiatr Neurosci 2015; 40(5): 291-3.

10. Cañas JJ, Quesada JF, Antolí A, Fajardo I. Cognitive flexibility and adaptability to environmental changes in dynamic complex problem-solving tasks. Ergonomics 2003; 46(5): 482-501.

11. Deák GO. The development of cognitive flexibility and language abilities. Adv Child Dev Behav 2003; 31: 271-327.

12. Stenger M. 7 Ways to develop cognitive flexibility [Internet]. Sydney, Australia: InformED, Open Colleges; 2017 Apr-[cited 2020 Oct 23]. Available from: https://www.opencolleges.edu.au/informed/ features/7-ways-develop-cognitive-flexibility/

13. Dong G, Potenza MN. A cognitive-behavioral model of Internet gaming disorder: theoretical underpinnings and clinical implications. J Psychiatr Res 2014; 58: 7-11.

14. Wei L, Zhang SY, Turel O, Bechara A, He QH. A tripartite neurocognitive model of Internet gaming disorder. Front Psychiatr 2017; 8(285): 1-11.

15. Benarous X, Morales P, Mayer H, Iancu C, Edel Y, Cohen D. Internet gaming disorder in adolescents with psychiatric disorder: two case reports using a developmental framework. Front Psychiatr 2019; 10: $1-9$.

16. Ge X, Sun Y, Han X, et al. Difference in the functional connectivity of the dorsolateral prefrontal cortex between smokers with nicotine dependence and individuals with Internet gaming disorder. $B M C$ Neurosci 2017; 18(1):1-10.

17. Bavelier D, Achtman RL, Mani M, Föcker J. Neural bases of selective attention in action video game players. Vision Res 2012; 61: 132-43. 
18. Ko $\mathrm{CH}$, Liu GC, Hsiao $\mathrm{S}$, et al. Brain activities associated with gaming urge of online gaming addiction. J Psychiatr Res 2009; 43(7): 739-47.

19. Sharifat H, Rashid AA, Suppiah S. Systematic review of the utility of functional MRI to investigate Internet addiction disorder: Recent updates on resting state and task-based fMRI. Malaysian J Med Health Sci 2018; 14(1): 2-33.

20. Young KS. Internet addiction: The emergence of a new clinical disorder. CyberPsychology Behaviour 1998a; 1(3): 237-244.

21. Young KS. Caught in the net: How to recognize the signs of Internet addiction and a winning strategy for recovery. New York: J. Wiley, 1998b: 256.

22. Guan NC, Isa SM, Hashim AH, Pillai SK. Validity of the Malay version of Internet addiction test: A study on a group of medical students in Malaysia. Asia Pac J Pub Health. 2012; 1-10.

23. Pontes HM, Griffiths MD. Measuring DSM-5 Internet gaming disorder: Development and validation of a short psychometric scale. Computers in Human Behavior 2015; 45: 137-43.

24. Monacis L, De Palo V, Griffiths MD, Sinatra M. Validation of the Internet gaming disorder scale-short form (IGDS9-SF) in an Italian-speaking sample. $J$ Behav Addict 2016; 5(4): 1-8.

25. Osman A, Bagge CL, Guitierrez PM, Konick LC, Kooper BA, Barrios FX. The suicidal behaviors questionnaire-revised (SBQ-R): Validation with clinical and nonclinical samples. Assessment 2001; 5: 443-54.

26. Lovibond SH, Lovibond PF. 1995. Manual for the depression anxiety \& stress scales. 2nd ed. Sydney: Psychology Foundation of Australia.

27. Zhang Y, Mei W, Zhang JX, Wu Q, Zhang W. Decreased functional connectivity of insula-based network in young adults with internet gaming disorder. Exp Brain Res 2016; 234(9): 2553-60.

28. Gläscher JP, Gitelman D. Contrast weights in flexible factorial design with multiple groups of subjects. 2008; 1-13. http://www.nemotos.net > resources > conweights

29. Brett M, Anton J, Valabregue R, Poline J. Region of interest analysis using an SPM toolbox. [Abstact]. 8th International Conference on Functional Mapping of the Human Brain. 2002; 6(2): 497.

30. Chou C, Hsiao MC. Internet addiction, usage, gratification and pleasure experience: The Taiwan college students' case. Computers \& Education 2000; 35(1): 65-80.

31. Young KS. Internet addiction: A new clinical phenomenon and its consequences. Am Behavior Scientist 2004; 48 (4): 402-15.

32. Griffiths MD. A 'components' model of addiction within a biopsychosocial framework. $J$ Substance Use 2005; 10: 191-7.

33. Király O, Griffiths MD, Urbán R et al. Problematic Internet use and problematic online gaming are not the same: Findings from a large nationally representative adolescent sample. Cyberpsychology Behavior Social Networking 2014; 17(12): 749-75412.

34. Ko CH, Yen JY, Yen CF, Chen CS, Wang SY. The association between Internet addiction and belief of frustration intolerance: The gender difference. CyberPsychology \& Behavior. 2008; 11(3): 273-8.

35. Nayak RD. Internet addiction a comparative study between undergraduate students of India and Malaysia. Int J Indian Psychol 2015; 2(4): 116-120.

36. Rosliza AM, Ragubathi MN, Mohamad YMKA, Shaharuddin MS. Internet addiction among undergraduate students : Evidence from a Malaysian public university. Int Med J Malaysia 2018; 17(2): 41-8.

37. Lee HK, Lee SY, Lee BH, Kim EB. Comparative investigation of prevention policy on Internet game addiction problems (Rep. No. 16-3). Seoul, South Korea: The National Assembly of the Republic of Korea, Gender Equality and Family Committee. 2017.

38. Li H, Wang $\mathrm{S}$. The role of cognitive distortion in online game addiction among Chinese adolescents. Children and Youth Services Review 2014; 35 (9): 1468-75.

39. Spekman ML, Konijn EA, Roelofsma PH, Griffiths MD. Gaming addiction, definition and measurement: A large-scale empirical study. Computers in Human Behavior 2013; 29(6): 2150-5.

40. Porter G, Starcevic V, Berle D, Fenech P. Recognizing problem video game use. Australian NZJ Psychiatry 2010; 44(2):120-8.

41. Dong G, Zhou H, Zhao X. Male internet addicts show impaired executive control ability: Evidence from a color-word Stroop task. Neurosci Lett 2011; 499(2): 114-8.

42. Metcalf O, Pammer, K. Impulsivity and related neuropsychological features in regular and addictive first person shooter gaming. CyberPsychology \& Behavior 2014; 17 (3): 147-52.

43. Wang L, Wu L, Wang Y, et al. Altered brain activities associated with craving and cue reactivity in people with Internet gaming disorder: Evidence from the comparison with recreational Internet game users. Front Psychol 2017; 8(7): 1-12.

44. Dong G, Hu Y, Lin X, Lu Q. What makes Internet addicts continue playing online even when faced by severe negative consequences? Possible explanations from an fMRI study. Biol Psychol 2013; 94(2): 282-9.

45. Xing L, Yuan K, Bi Y, et al. Reduced fiber integrity and cognitive control in adolescents with Internet gaming disorder. Brain Res 2014; 1586: 109-17.

46. Le TH, Pardo JV, Hu X. 4 T-fMRI Study of nonspatial shifting of selective attention: cerebellar and parietal contributions. J Neurophysiol 1998; 79(3): 1535-48.

47. Yusoff AN, Mohamad M. Pengimejan resonans magnet kefungsian. Cetakan Pertama. Bangi: Penerbit Universiti Kebangsaan Malaysia, 2019: 202.

48. Dong G, Devito EE, Du X, Cui Z. Impaired inhibitory control in 'Internet addiction disorder': A functional magnetic resonance imaging study. Psychiatry Res 2012; 203(2-3): 153-8.

49. Meng Y, Deng W, Wang H, Guo W, Li T. The prefrontal dysfunction in individuals with Internet gaming disorder: A meta-analysis of functional magnetic resonance imaging studies. Addict Biol 2015; 20(4): 799-808.

50. Dong G, Li H, Wang L, Potenza MN. Cognitive control and reward/loss processing in Internet gaming 
disorder: Results from a comparison with recreational internet game-users. Eur Psychiatry 2017; 44: 30-8.

51. Bressler SL, Menon V. Large-scale brain networks in cognition: Emerging methods and principles. Trends Cogn Sci 2010; 14(6): 277-90.

52. Menon V. Large-scale brain networks and psychopathology: A unifying triple network model. Trends Cogn Sci 2011; 15(10): 483-506.

53. Leménager T, Dieter J, Hill H, et al. Exploring the neural basis of avatar identification in pathological Internet gamers and of self-reflection in pathological social network users. J Behav Addict 2016; 5(3): 485-99.

54. Lutz K, Widmer M. What can the monetary incentive delay task tell us about the neural processing of reward and punishment? Neurosci Neuroeconomics 2014; 3: 33-45.

55. Chelazzi L, Corbetta M. Cortical mechanisms of visuospatial attention in the primate brain. In: Gazzaniga MS, eds: The new cognitive neurosciences (2nd edition), Cambridge: MIT Press, 2000: 667-86.

56. Vossel S, Thiel CM, Fink GR. Cue validity modulates the neural correlates of covert endogenous orienting of attention in parietal and frontal cortex. Neuroimage 2006; 32(3): 1257-64.

57. Mitchell RLC. The BOLD response during Stroop task-like inhibition paradigms: Effects of task difficulty and task-relevant modality. Brain Cogn 2005; 59(1): 23-37.

58. Yuan K, Yu D, Cai C, et al. Frontostriatal circuits, resting state functional connectivity and cognitive control in Internet gaming disorder. Addict Biol 2017; 22(3): 813-22.

59. Caufield MD, Servatius RJ. Focusing on the possible role of the cerebellum in anxiety disorders. In: Durbano F; eds: New insights into anxiety disorders, London (UK): InTech, 2013: 42-70.

60. Marvel CL, Desmond JE. The contributions of cerebro-cerebellar circuitry to executive verbal working memory. Cortex 2010; 46(7): 880-95.

61. Moberget T, Karns CM, Deouell LY, Lindgren M, Knight RT, Ivry RB. Detecting violations of sensory expectancies following cerebellar degeneration: a mismatch negativity study. Neuropsychologia 2008; 46(10): 2569-79.

62. Schmahmann JD, Caplan D. Cognition, emotion and the cerebellum. Brain 2006; 129(2): 290-2.

63. Annoni JM, Ptak R, Caldara-Schnetzer AS, Khateb A, Pollermann BZ. Decoupling of autonomic and cognitive emotional reactions after cerebellar stroke. Ann Neurol 2003; 53(5): 654-8.

64. Schmahmann JD. Disorders of the cerebellum: Ataxia, dysmetria of thought, and the cerebellar cognitive affective syndrome. J Neuropsychiatry Clin Neurosci 2004; 16(3): 367-78.

65. Moreno-Rius J. The cerebellum under stress. Front Neuroendocrinol 2019; 54: 100774.

66. Hussain Z, Griffiths MD, Baguley T. Online gaming addiction: classification, prediction and associated risk factors. Addict Res Theory 2012; 20(5): 359-71.

67. Lee K, Lee KH, Gyeong H, Yu B, Song YM, Kim D. Reliability and validity of the Korean version of the Internet addiction test among college students. J Korean Med Sci 2013; 28(5): 763-8.
68. Choo H, Sim T, Liau AKF, Gentile DA, Khoo A. Parental influences on pathological symptoms of video-gaming among children and adolescents: A prospective study. J Child Family Studies 2015; 24(1): 1429-41.

69. Lee D, Lee J, Lee JE, Jung YC. Altered functional connectivity in default mode network in Internet gaming disorder: Influence of childhood ADHD. Prog Neuro-Psychopharmacol Biol Psychiatry 2017; 75: $135-41$.

70. American Psychiatric Association, DSM-5 Task Force. (2013). Diagnostic and statistical manual of mental disorders: DSM-5 ${ }^{\mathrm{TM}}$ (5th ed.). American Psychiatric Publishing, Inc.

71. Kim NR, Hwang SSH, Choi JS, et al. Characteristics and psychiatric symptoms of Internet gaming disorder among adults using self-reported DSM-5 criteria. Psychiatry Investig 2016; 13(1): 58-66.

72. Han DH, Bae S, Hong J, Kim SM, Son YD, Renshaw P. Resting-state fMRI study of ADHD and internet gaming disorder. J Atten Disord 2021; 25(8): 108095.

73. Hupfeld K, Abagis T, Shah P. Living "in the zone": Hyperfocus in adult ADHD. ADHD Attention Deficit and Hyperactivity Disorders 2019; 11: 191-208. 